\title{
FORMAÇÃO EM ENFERMAGEM E IDENTIDADE PROFISSIONAL: TRAÇOS SOCIAIS, ACADÉMICOS, PERCEÇÕES E ATRIBUTOS LIGADOS À PROFISSÃO
}

TRAINING IN NURSING AND PROFESSIONAL IDENTITY: SOCIAL TRAITS, ACADEMICS, PERCEPTIONS AND ATTRIBUTES LINKED TO THE PROFESSION

FORMACIÓN EN ENFERMERÍA E IDENTIDAD PROFESIONAL: TRAZOS SOCIALES, ACADÉMICOS, PERCEPCIONES Y ATRIBUTOS VINCULADOS A LA PROFESIÓN

\author{
Maria Helena Pimentel (hpimentel@ipb.pt)* \\ Carlos Miguel Figueiredo Afonso (carlos.afonso@ipb.pt)* \\ Ana Margarida P. Caetano Monteiro (anamargaridamonteiro44@gmail.com)*
}

\section{RESUMO}

\begin{abstract}
Questiona-se em que medida a formação em enfermagem poderá contribuir para a renovação das representações e da identidade profissional. Objetivo: identificar uma tipologia de estudantes de enfermagem de acordo com os seus traços sociais, académicos, perceções e atributos ligados à profissão.
\end{abstract}

Metodologia: Aplicou-se um questionário a 224 estudantes de enfermagem, a totalidade dos alunos do 1o ano (176) e do 40 ano (48), sendo excluídos os restantes. Foi aplicada a Resilence Scale (RS) Wagnilg e Young (1993), validada para a população portuguesa por Ferreira de Carvalho e Pereira (2012) e a Escala de Satisfação com o Suporte Social (ESSS) (Pais Ribeiro, 1999). Com base nas dimensões desta última escala, procedeu-se à análise de clusters através do método de Ward. Foram também realizados testes estatísticos para comparar os grupos em diferentes indicadores.

Resultados: Da análise de clusters realizada, obteve-se uma solução de agrupamento de 3 grupos: “ devotos blindados socialmente", "devotos com menos suporte social" e "os que querem mudar".

Conclusão: As atitudes e afinidade em relação à enfermagem como profissão é produzida pela articulação das trajetórias individuais, sendo que o suporte social é um elemento diferenciador neste âmbito, tendo influência na sua resiliência e perceções. Ao invés, a formação em enfermagem não se revelou decisiva na afirmação da identidade profissional.

Palavras Chave: resiliência, suporte social, formação em enfermagem, identidade profissional.

\section{ABSTRACT}

It is questionable to what extent nursing training can contribute to the renewal of representations and professional identity. Objective: to identify a typology of nursing students according to their social and academics traits, perceptions and attributes related to the profession. 
Methodology: A questionnaire answered by 224 nursing students, the total number of students in the 1st year (176) and the 4th year (48), the remaining, and the application of the Resilience Scale (RS) by Wagnild and Young (1993), validated for the Portuguese population by Ferreira de Carvalho and Pereira (2012), as well as the Social Support Satisfaction Scale (ESSS) (Pais Ribeiro, 1999). Based on the dimensions of this latest scale, the clusters were analyzed using the Ward method. Statistical tests were also performed to compare different indicators from the groups.

Results: From the analysis of the clusters, we obtained a grouping solution comprising 3 groups: "socially shielded devotees", "devotees with less social support" and "those who want to change".

Conclusion: The attitudes and affinity towards nursing as a profession is produced by the interlinking of individual trajectories, social support being a differentiating element in this regard and having an influence on their resilience and perceptions. On the other hand, nursing education was not decisive in affirming professional identity.

Keywords: resilience, social support, training in nursing, professional identity.

\section{RESUMEN}

Se ha cuestionado en qué medida la formación en enfermería puede influir en la renovación de la identidad profesional. Objetivo: definir el perfil de los estudiantes de enfermería en función de su nivel social, nivel académico, sus percepciones y características profesionales.

Se aplicaron dos escalas a una muestra de 224 estudiantes de enfermería la totalidad de los alumnos del primer año (176) y del 4o año (48), quedando excluidos los restantes. La primera de ellas fue la Resilence Scale (RS) de Wagnild y Young (1993), validada para la población portuguesa por Ferreira de Carvalho y Pereira (2012); y la segunda, la Escala de Satisfacción con el Apoyo Social (ESSS) de País Ribeiro (1999). Se llevó a cabo un análisis de clusters a través del método de Ward, fundamentado en las dimensiones de la escala ESSS. Además, se realizaron análisis estadísticos para comparar varios indicadores entre los diferentes grupos.

El análisis de clusters dio como resultado la creación de 3 grupos: 'protegidos socialmente', 'con menos apoyo social' $y$ 'los que quieren cambio'.

Las actitudes y la afinidad hacia la enfermería como profesión se construyen por la trayectoria individual, siendo el apoyo social un factor diferenciador que influye en la resiliencia y las percepciones de estos individuos. En cambio, la formación en enfermería no se reveló decisiva en la afirmación de la identidad profesional.

Palabras clave: resiliencia, apoyo social, formación en enfermería, identidad profesional.

|*Escola Superior de Saúde - Instituto Politécnico de Bragança.

Submitted: 05h March 2019

Accepted: 16th June 2019 


\section{INTRODUÇÃO}

Diferentes contextos de vida, nomeadamente o contexto académico do ensino superior, expõem os jovens a exigências e riscos. Por isso, a sua resiliência é fundamental (Soares, Pereira e Canavarro, 2014). As dificuldades experienciadas podem desencadear problemas de ordem académica, de relacionamento interpessoal, de autonomia, de autoestima e de stress tendo o suporte social papel protetor (Pais Ribeiro, 2011; Bachi \& Licinio, 2016).

Resiliência é um termo que habitualmente designa (na física) a resistência de um material a choques elevados e a sua capacidade para absorver a energia cinética do meio modificandose mas retornando posteriormente ao formato original como o elástico que, após uma tensão inicial, volta ao mesmo estado. Na metalurgia encontra-se associado à capacidade de um material voltar ao estado inicial após pressões deformadoras. Em saúde remete para a capacidade de resistir a uma doença, não sendo, no entanto, a simples capacidade de resistência (na ideia de rigidez), mas englobando a maleabilidade e capacidade de adaptação para enfrentar positivamente acontecimentos adversos numa perspetiva de promoção da saúde, bem-estar e qualidade de vida (Ferreira de Carvalho e Pereira, 2012).

Resiliência pode ser definida como capacidade de adaptação após (ou nas) adversidades, estando conotada com a ideia de força interior, competência, flexibilidade, coping bemsucedido (Wagnild \& Collins, 2009). Segundo os mesmos autores em sentido inverso à resiliência encontra-se negativamente associada a depressão, perceção de stresse e ansiedade.

O suporte social refere-se aos recursos materiais e psicológicos a que o individuo tem acesso através da sua rede social (Siqueira, 2008). Em contexto académico, o suporte social é importante nos processos adaptativos do indivíduo e assume um papel particularmente importante para os estudantes de enfermagem. A perspetiva de saber lidar com a morbilidade torna-se real para os estudantes desta área formativa, uma vez que, necessitam de estar preparados para conviver com pressões no trabalho que por sua vez podem afetar a saúde mental (Carvalho et al, 2016). Na presenta pesquisa, considera-se que confiar no pressuposto de que se é querido, amado e estimado pode ser um importante fator de proteção para o estudante de enfermagem no seu sucesso académico e realização pessoal, uma vez que existe uma perspetiva de auxílio e apoio através da sua rede social.

É possível definir suporte social, apesar de ser um conceito multidimensional e subjetivo, como "a existência ou disponibilidade de pessoas em quem se pode confiar, pessoas que nos mostram que se preocupam connosco, nos valorizam e gostam de nós" (Sarason et al, 1983, p.127, apud Pais-Ribeiro, 2011) e satisfação com o suporte social como a expressão de utilidade e nível de ajuda sentidos pelo indivíduo perante o suporte social disponível (Trivete, 1990 apud Pais-Ribeiro, 2011).

Deste modo, estudar e obter informação útil e segmentada sobre a resiliência e o suporte social dos estudantes de enfermagem, poderá ser um bom ponto de partida para compreender o processo formativo no sentido de saber como o estudante lida com as situações potencialmente stressantes que se podem agudizar aquando na sua aprendizagem de carater mais prático.

Ao longo da nossa atividade como docentes foi-nos dado testemunhar que há alunos que iniciam o curso de enfermagem com algumas incertezas. É na tentativa de encontrar resposta para estas incertezas que formulamos o seguinte objetivo de investigação: identificar uma tipologia de estudantes de enfermagem de acordo com os seus traços sociais, académicos, perceções e atributos ligados à profissão. 


\section{ENFERMAGEM, FORMAÇÃO, IDENTIDADE E REPRESENTAÇÕES}

A emergência da enfermagem, enquanto grupo-socioprofissional, está intimamente ligada à expansão do sistema hospitalar ocorrida a partir do século XIX, assim como às transformações técnicas e sociais que estiveram na origem dessa expansão (Sheila \& Padilha, 2016; Pimentel et al, 2011). Verificou-se nesta altura uma reorganização do modo da produção de cuidados, quer através do aumento da complexidade técnica dos cuidados de saúde, decorrentes da institucionalização da moderna medicina, quer ainda pelo aumento da complexidade administrativa e pela burocratização organizacional do sistema hospitalar. Isso veio exigir à enfermagem competências e responsabilidades para as quais ainda não se encontrava preparada, uma vez que, os cuidados de enfermagem eram prestados por "religiosas" ou por pessoal "não diferenciado" que, até essa altura, asseguravam as prestações não médicas. Foi precisamente neste contexto técnico e organizacional que se desencadeou a "reforma" de Florence Nigthingale, da qual resultou uma reelaboração da natureza dos cuidados de enfermagem, concretizada na sua progressiva dissociação do trabalho doméstico a que estivera associado. Esta demarcação constituiu-se uma referência fundamental no sentido da construção de uma identidade como grupo socioprofissional.

Ao refletir sobre a especificidade da construção da identidade profissional dos enfermeiros Collière (2000) assinala três tipos de preocupações:

1. A preocupação de construir um exercício específico da enfermagem, conducente à "demarcação do ascendente médico".

2. A aquisição de uma formação superior. $O$ acesso à universidade permitiu ao enfermeiro sair do espaço unidimensional do hospital/escola e libertar-se da uniformização dos modelos sociais que este traduz, para descobrir a plurivalência de correntes de pensamento, a sua diversidade, a sua contradição, a sua oposição, bem como as diferentes opções sociais, económicas e políticas subjacentes. A formação universitária inicia o processo interrogativo, obriga a questionar, incita à argumentação. É pela formação universitária que a profissão de enfermagem adquire experiência no processo científico.

3. A preocupação em valorizar a investigação profissional como atitude sistemática do problema das práticas. A investigação permite ao enfermeiro melhor compreender a natureza dos cuidados e agir sobre as condições de trabalho indispensáveis para os realizar e para melhor os viver, conquistando condições para que os seus saberes sejam construídos por eles próprios e não sejam subprodutos de outros saberes.

Ao acompanharem a evolução dos cuidados, os enfermeiros pretendem libertar-se de uma prática clínica de rotinas hospitalares, em que o enfermeiro complementa o trabalho do médico e obedece cegamente às ordens instituídas e institucionalizadas tornando a sua prática reflexiva e autónoma, participando nas políticas de saúde, as quais devem ser perfeitamente ajustadas às necessidades dos utilizadores.

Porém, o "papel" do enfermeiro continua rodeado de controvérsias. Para se tentar compreender as conceções que acompanham o desenvolvimento das práticas profissionais dos enfermeiros, torna-se importante identificar quais as conceções profissionais subjacentes à construção da identidade profissional, não só no que se relaciona com a aquisição e desenvolvimento de valores morais e sociais, mas também em relação aos conhecimentos teóricos e práticos, considerando que, quer as conceções ideológicas que envolvem as 
conceções acerca da enfermagem como profissão, quer as estratégias de atuação desenvolvidas, vão condicionar a sua autonomia e, consequentemente, a sua identidade.

O desejo de conhecer os elementos significativos da identidade de um grupo é, muitas vezes, desencadeado pela necessidade de conhecer as suas dinâmicas, tensões, conflitos, representações e transformações. Convém, no entanto, notar que a noção de identidade, sendo extremamente complexa, é objeto de uma grande diversidade de abordagens científicas e, se bem que a maior parte dos autores atribuam ao conceito uma pluralidade de dimensões, as investigações sobre este tema dão relevância quer aos elementos intrapsíquicos, quer ainda aos processos de interação entre estes dois grupos de elementos (Erikson, 1976).

O processo identitário é, pois, algo complexo, eminentemente relacional e que implica, segundo Pinto (1991, p. 218), "a imbricação de dois processos: o processo pelo qual os atores sociais se integram em conjuntos mais vastos, de pertença ou de referência, com eles se fundindo de modo tendencial (processo de identificação); e o processo através do qual os agentes tendem a automatizar-se e diferenciar-se socialmente, fixando em relação aos outros distâncias e fronteiras mais ou menos rígidas (processo de identização)". A construção de identidades alimenta-se sempre de "alteridades (reais ou de referência) e por isso nunca exclui em absoluto convivências e infidelidade recíprocas para desespero dos que ainda querem ver o desenvolvimento harmonioso e coerente de umas tantas substâncias essenciais" (Pinto, 1991:219). Neste contexto como refere o mesmo autor, a identidade não é mais do que o resultado ao mesmo tempo estável e provisório, individual e coletivo, subjetivo e objetivo, biográfico e estrutural, dos diversos processos de socialização que, em conjunto, constroem os indivíduos e definem as instituições.

A identidade tem duas funções: a integradora e a adaptativa. A primeira define-se pela preservação do "Eu" como unidade integrada; a segunda permite a adaptação do indivíduo a situações relacionais. A identidade social tenta adaptar-se às normas, valores e modelos sociais, mas ao mesmo tempo confere ao indivíduo a possibilidade de agir como ser único e diferente dos seus semelhantes.

Dubar (2009) refere que a noção de identidade está ligada às posições que o indivíduo ocupa na sociedade. A identidade abrange, segundo este autor, três dimensões: o estatuto - posição na estrutura social; o valor - referente ao papel que o indivíduo desempenha na estrutura social (ao papel associam-se expectativas que exprimem juízos de valor); e a implicação - referente à importância do papel para a pessoa visada, a qual se manifesta em termos de desempenho. A partir destas três dimensões é possível apreender a identidade de qualquer indivíduo.

Na medida em que o objeto do nosso estudo se desenvolve em torno de pessoas que ainda não são profissionais, a formação, entendida como socialização profissional, exerce uma função antecipatória, porque permite pensar, quer no conjunto das ideias originárias e das perspetivas acerca da profissão que virão a exercer, quer no investimento pessoal e profissional, que tem subjacente um dispositivo identitário relacionado com as representações sociais e o estatuto atribuído à profissão.

Há, contudo, inúmeros fatores implicados no desenvolvimento da identidade pessoal e social, logo não podemos separar a problemática identitária dos enfermeiros do desenvolvimento histórico da profissão, porque nos parece haver uma grande relação entre ambas. É que, apesar da crescente valorização da enfermagem ao nível da formação verificada em Portugal, a prática da enfermagem tem evoluído mais por ação da evolução social das novas necessidades, das novas doenças e dos novos meios de as tratar postos à disposição das pessoas, do que pelo progresso intrínseco da própria profissão. A identidade profissional do enfermeiro envolve um vasto campo de relação do grupo profissional com um conjunto de 
espaços sociais através dos quais produz e reproduz determinadas relações com os saberes que Ihe são específicos, com as condições simbólicas e imaginárias que tendem a definir a sua especificidade profissional, com os contextos sócio-técnico-organizacionais do exercício do trabalho futuro (Sheila \& Padilha, 2016).

Assim, a socialização profissional dos enfermeiros começa na sua formação inicial. Em Portugal, o Ensino de Enfermagem sofreu significativas alterações, assinaladas, por um lado, pelo progressivo aumento da escolaridade básica obrigatória para o acesso ao Curso de Enfermagem, e que veio a culminar na sua integração no Sistema Educativo Nacional ao nível do Ensino Superior Politécnico (Dec. Lei, n.o 480/88 de 23 de dezembro), até então da responsabilidade do Ministério da Saúde, e por outro lado, pela progressiva reformulação dos planos curriculares, através do alargamento da componente teórica da formação e da crescente ênfase atribuída à preparação profissional na promoção da saúde e à própria filosofia do ser Enfermeiro.

O curso de enfermagem encontra-se organizado por áreas específicas que se interrelacionam e que funcionam como unidades estruturantes do saber, desenvolvendo-se do geral para o específico, e sempre através de duas componentes: o ensino teórico e o ensino clínico. O ensino teórico, sendo da responsabilidade e competência dos enfermeiros docentes, inclui a colaboração de outros profissionais com formação técnica e científica diferenciada, constituindo equipas multidisciplinares. Pretende-se que a abordagem teórica seja desenvolvida seguindo a perspetiva dos modelos teóricos para a enfermagem, com a finalidade de os estudantes adquirirem conhecimentos, aptidões e atitudes profissionais. Estes modelos apoiam-se em teorias essencialmente oriundas das ciências sociais e humanas, têm em comum uma perspetiva de cuidados centrados na pessoa como sujeito ativo desses mesmos cuidados e defendem uma relação de parceria entre quem presta e quem recebe cuidados (Sheila \& Padilha, 2016; Pires, 2009; Pimentel el al, 2011). O ensino clínico, constituindo cerca de cinquenta por cento da formação do aluno, decorre em diferentes contextos da atividade profissional do enfermeiro, desenvolvendo-se sob a responsabilidade dos enfermeiros docentes, com a colaboração de enfermeiros das instituições de saúde em que se realiza. Preconiza-se que o ensino clínico seja organizado de forma a permitir um conjunto coerente nos domínios cognitivos, afetivo e psicomotor, com responsabilização progressiva, garantindo a possibilidade de realização de ações relativas à prevenção da doença, promoção, manutenção e recuperação da saúde.

A preocupação com o desenvolvimento de competências transversais e específicas ao longo do percurso académico tem-se tornado, por isso, uma preocupação crescente, quer nacional quer internacionalmente (Savoji \& Ganji, 2013; Selemat, Ismail, Ahmad, Hussin, Seliman, 2013; Shek, 2013). Vários têm sido os autores que têm realçado a importância dos currículos de cursos superiores integrarem o desenvolvimento de competências pessoais e interpessoais que, tornando-se ferramentas úteis para os estudantes, aumentem o sucesso académico e profissional, prevenindo também o desajustamento psicoemocional e por consequência riscos associados à saúde. De acordo com os autores acima referenciados, o ambiente académico (rendimento, expectativas, adaptação e satisfação), familiar (suporte social, separação psicológica e vinculação) e social (relacionamento com os pares, integração social e envolvimento em atividades e grupos sociais), influenciam os contextos de adaptação.

Também, a compreensão dos fenómenos representacionais no campo da Enfermagem, e mais concretamente no ensino de enfermagem, constituiu matéria de estudo por parte de várias autoras (Bevis, 2005; Ha \& Nuntaboot, 2016; Fonseca et al, 2013, Brodie et al, 2004; Silva \& Ferreira, 2012) ao tentarem fazer a articulação entre a teoria e a prática no processo educativo. 


\section{MÉTODOS}

\subsection{Desenho do estudo e fonte de dados}

A população em estudo é constituída por estudantes de licenciatura de enfermagem de uma Escola de Saúde do Interior Norte de Portugal, 468 inscritos.

Pelo interesse em verificar se a formação interfere nas conceções acerca da profissão, entre os alunos recém-chegados à Escola evitando, assim, como refere Fonseca et al, (2013), qualquer contaminac, ão das construções previamente elaboradas e aqueles que se encontram a finalizar o curso, apropriados de saberes construídos e alicerçados na compreensão dos fenómenos representacionais no campo da Enfermagem e mais concretamente no ensino de enfermagem (Bevis, 2005; Ha \& Nuntaboot, 2016; Fonseca et al, 2013, Brodie et al, 2004; Silva \& Ferreira, 2012), a amostra inclui a totalidade dos alunos do 10 ano (176) e do 4ㅇano (48), sendo excluídos os restantes.

Estudo quantitativo, descritivo e analítico com recurso a questões de caraterizac,ão sociodemográfica e académica. Recorreu-se, ainda, à Resilence Scale (RS) (Wagnilg e Young (1993), validada para a população portuguesa por Ferreira de Carvalho \& Pereira, 2012) e Escala de Satisfação com o Suporte Social (ESSS) (Wethingson \& Kessler, 1986, validada para a população portuguesa por Pais Ribeiro, 1999).

A The Resilience Scale (RE), na sua versão original, procura medir níveis de adaptação psicossocial positiva em situações e eventos de vida adversos através de 25 itens descritos de forma positiva com respostas tipo Likert, numa escala ordinal desde 1 (discordo totalmente) a 7 (concordo totalmente). Os valores totais são obtidos por somatório dos valores das respostas obtidas e podem variar entre 25 a 175, em que valores altos equivalem a elevada resiliência. Essa escala permite identificar o grau de resiliência individual enquanto característica positiva da personalidade e promotora da adaptação.

A Escala de Satisfação com o Suporte Social (ESSS) permite a operacionalização da variável satisfação com o suporte social em quatro dimensões, designadamente: Satisfação com Amigos (SA); Intimidade (IN); Satisfação com a Família (SF) e Atividades Sociais (AS), através de 15 itens de diferencial semântico de 5 pontos.

A pontuação tołal da escala resulta da soma da totalidade dos itens podendo variar entre $15 \mathrm{e}$ 75 , sendo que à pontuação mais elevada corresponde uma maior perceção de suporte social. Para encontrar a pontuação de cada dimensão/subescala ou a pontuação total, devem somarse os itens que a constituem. Dado que o número de itens de cada dimensão é diferente, as pontuações mínimas e máximas por dimensão também o são ("SA" - mínimo: 5 pontos; máxima: 25 pontos "IN" - mínimo: 4 pontos; máxima: 20 pontos, "SF" - mínimo: 3 pontos; máxima: 15 pontos, "AS" - mínimo: 3 pontos; máxima: 15 pontos) (Pais Ribeiro, 1999).

\subsection{Análise estatística}

Procedeu-se à análise descritiva da amostra através de tabelas de frequência (no caso das variáveis de natureza qualitativa) e da análise da média e desvio padrão (no caso das variáveis de natureza quantitativa).

Para a construção de uma tipologia de estudantes de enfermagem foi necessário partir para uma análise de clusters e identificar classes, subconjuntos de registos que representam 
valores mais próximos em certos atributos, produzindo assim um esquema de agrupamento que proporciona o conjunto de dados em classes (Marôco, 2014). Muito embora a análise de clusters seja uma metodologia de análise multivariada normalmente utilizada na área do marketing para proceder à segmentação do mercado a partir de características dos consumidores, a sua utilização justifica-se no contexto da presente investigação, uma vez que se pretende obter uma tipologia de estudantes de enfermagem de acordo com as suas características académicas, sociais e perceções sobre a enfermagem.

Perante esta perspetiva de realização de um clustering à amostra de estudantes de enfermagem, tomou-se a opção metodológica de apenas realizar essa análise aos estudantes que não têm intenção de de mudar de área profissional e fixou-se a subamostra dos estudantes que têm a intenção de mudar de área profissional para uma comparação posterior com os restantes grupos retidos pela solução de agrupamento. Procedeu-se assim a uma análise de clusters utilizando o método de Ward, tendo como variáveis de segmentação as subescalas de satisfação com o suporte social. O método de Ward consiste num procedimento de agrupamento hierárquico no qual a medida de similaridade usada para juntar agrupamentos é calculada como a soma de quadrados entre os dois agrupamentos feita sobre todas as variáveis. Esse método tende a resultar em agrupamentos de tamanhos aproximadamente iguais devido à sua minimização de variação interna. Em cada estádio combinam-se os dois agrupamentos que apresentarem menor aumento na soma global de quadrados dentro dos agrupamentos (Hair et a/2009).

Para caracterização e comparação dos grupos retidos na solução de agrupamento realizaramse, numa primeira instância, testes one-way ANOVA (para comparar o comportamento dos grupos nas variáveis de segmentação). Para obter informação comparativa em relação às características dos estudantes (traços sociais, antecedentes e perceções sobre enfermagem) realizaram-se testes de independência do Qui-Quadrado.

\section{APRESENTAÇÃO DE RESULTADOS}

Apresentam-se em primeiro lugar os traços sociodemográficos e académicos dos 224 estudantes universitários do curso de enfermagem ( Tabelas 1e 2).

Estamos perante uma amostra claramente feminizada $(82,6 \%$ dos estudantes inquiridos são do género feminino). Em termos etários a maioria dos estudantes (72,2\%) tem até 21 anos. Verifica-se que mais de três quartos dos estudantes $(78,6 \%)$ estão no primeiro ano do curso de enfermagem. No que respeita à proveniência dos estudantes, a maior parte $(60,2 \%)$ provém do meio urbano e de agregados familiares cujas categorias profissionais ${ }^{1}$ correspondem na sua maioria a empregados executores dos serviços e vendas (25,8\%), a ocupações elementares $(18,8 \%)$ e a operários $(13,1 \%)$. Examinando a proveniência dos estudantes verifica-se uma elevada representação de níveis intermédios de escolaridade dos pais ( Tabela †).

\footnotetext{
${ }^{1}$ Para a atribuição de uma categoria profissional ou grau de escolaridade ao agregado familiar recorreu-se a um procedimento da 'conjugação' com aspetos da dominância (atribuição ao grupo doméstico familiar da categoria de profissional/grau de escolaridade correspondente à do elemento que para ele contribui, em termos gerais, com maior volume de recursos).
} 


\begin{tabular}{|c|c|c|}
\hline & $\mathbf{n}$ & $\%$ \\
\hline \multicolumn{3}{|l|}{ Género $(n=224)$} \\
\hline Masculino & 39 & 17,4 \\
\hline Feminino & 185 & 82,6 \\
\hline \multicolumn{3}{|l|}{ Idade $(n=223)$} \\
\hline Até 21 anos & 161 & 72,2 \\
\hline Mais de 21 anos & 62 & 27,8 \\
\hline \multicolumn{3}{|l|}{ Ano do Curso $(n=224)$} \\
\hline 1o & 176 & 78,6 \\
\hline $4 \div$ & 48 & 21,4 \\
\hline \multicolumn{3}{|l|}{ Categoria profissional do agregado familiar $(n=213)$} \\
\hline Empresários e dirigentes liberais & 5 & 2,3 \\
\hline Profissionais das atividades científicas e intelectuais & 23 & 10,8 \\
\hline Técnicos e profissionais associados & 12 & 5,6 \\
\hline Trabalhadores de apoio administrativo & 14 & 6,6 \\
\hline Empregados executantes dos serviços e vendas & 55 & 25,8 \\
\hline Trabalhadores qualificados da agricultura, silvicultura e pesca & 3 & 1,4 \\
\hline Trabalhadores do artesanato e relacionados & 19 & 8,9 \\
\hline Operários & 28 & 13,1 \\
\hline Ocupações elementares & 40 & 18,8 \\
\hline Ocupações das forças armadas & 14 & 6,6 \\
\hline \multicolumn{3}{|l|}{ Local de Proveniência $(n=221)$} \\
\hline Meio Rural & 88 & 39,8 \\
\hline Meio urbano & 133 & 60,2 \\
\hline \multicolumn{3}{|l|}{ Habilitações dos pais [maior grau] $(n=215)$} \\
\hline Primária incompleta/Ensino primário & 34 & 15,8 \\
\hline 6ะ ano de escolaridade & 40 & 18,6 \\
\hline 9o ano de escolaridade & 49 & 22,8 \\
\hline 12: ano de escolaridade & 65 & 30,2 \\
\hline Curso superior & 27 & 12,6 \\
\hline \multicolumn{3}{|l|}{ Lugar que ocupa no agregado familiar $(n=215)$} \\
\hline Filho único & 55 & 24,7 \\
\hline Filho mais velho & 64 & 28,7 \\
\hline Filho do meio (entre outros) & 17 & 7,6 \\
\hline Filho mais novo & 87 & 39 \\
\hline
\end{tabular}

Tabela 1 - Caracterização social dos estudantes

Mencione-se em primeiro lugar que se registaram valores omissos nas variáveis 'idade', 'Categoria profissional do agregado familiar', 'local de proveniência', 'habilitação dos pais” e 'lugar que ocupa no agregado familiar'.

Verifica-se que $21,5 \%$ dos estudantes exerceram alguma atividade profissional antes de ingressar no curso de enfermagem e que $17,9 \%$ dos estudantes já estiveram matriculados noutro curso. Constata-se também que apenas $7,6 \%$ manifestou que a opção pelo curso de enfermagem não constituiu uma primeira escolha ( Tabela 2).

\begin{tabular}{lcc}
\hline & $\mathrm{n}$ & $\%$ \\
\hline Antes de ingressar no curso de enfermagem exerceu alguma atividade profissional? & & \\
Não & 175 & 78,5 \\
\hline Sim & 48 & 21,5 \\
\hline Esteve matriculado(a) noutro curso? & 184 & 82,1 \\
Não & 40 & 17,9 \\
\hline Sim & 17 & 7,6 \\
\hline A opção pelo curso de enfermagem constituiu uma primeira escolha? & 206 & 92,4 \\
\hline Não & & \\
\hline
\end{tabular}

Tabela 2 - Antecedentes dos estudantes 
Na informação gráfica que se segue (Figura 1e 2) são apresentados os coeficientes de fusão nas últimas etapas do processo aglomerativo por forma a obter informação sobre o número de clusters a reter através do método de Ward.

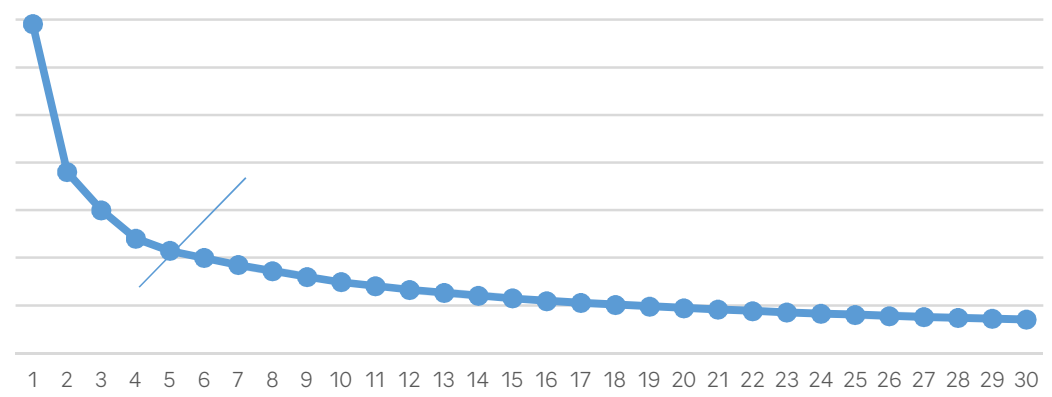

Figura 1: Distâncias entre os coeficientes de fusão

O eixo das coordenadas tende a ficar paralelo com o eixo das abcissas no segundo ponto do processo aglomerativo indiciando uma menor diferenciação entre os clusters e a consideração de uma solução de agrupamento com dois grupos retidos.

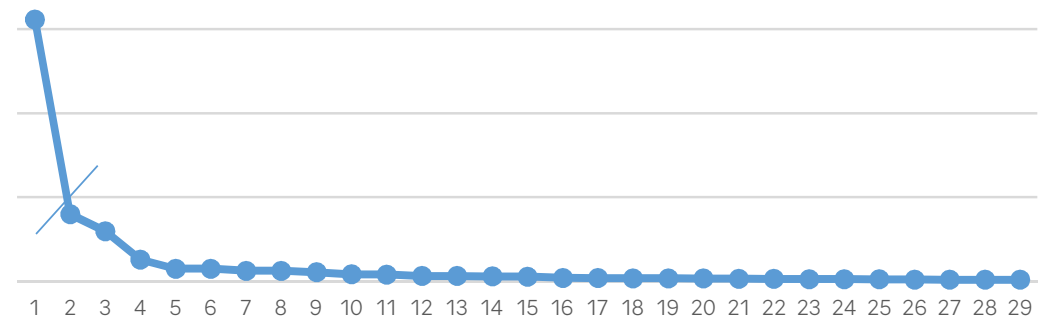

Figura 2: Diferenças entre os coeficientes de fusão

A análise da diferença entre os coeficientes de fusão vem a confirmar a retenção de dois grupos, uma vez que essas diferenças são muito baixas a partir do segundo ponto do processo aglomerativo.

Assim, a partir da representação do coeficiente de fusão (ou por via das diferenças entre os coeficientes) é possível concluir que segundo o método Ward escolher-se-iam dois grupos, pois a partir daí, os coeficientes são muito semelhantes, refletindo menor diferenciação entre os clusters.

Passa-se a apresentar a informação gráfica da Figura 3, que nos leva à denominação dos dois grupos retidos na solução de agrupamento. Essa tarefa será executada não só a partir do comportamento desses grupos nas variáveis de segmentação, mas também a partir da sua predisposição face ao curso de enfermagem. 

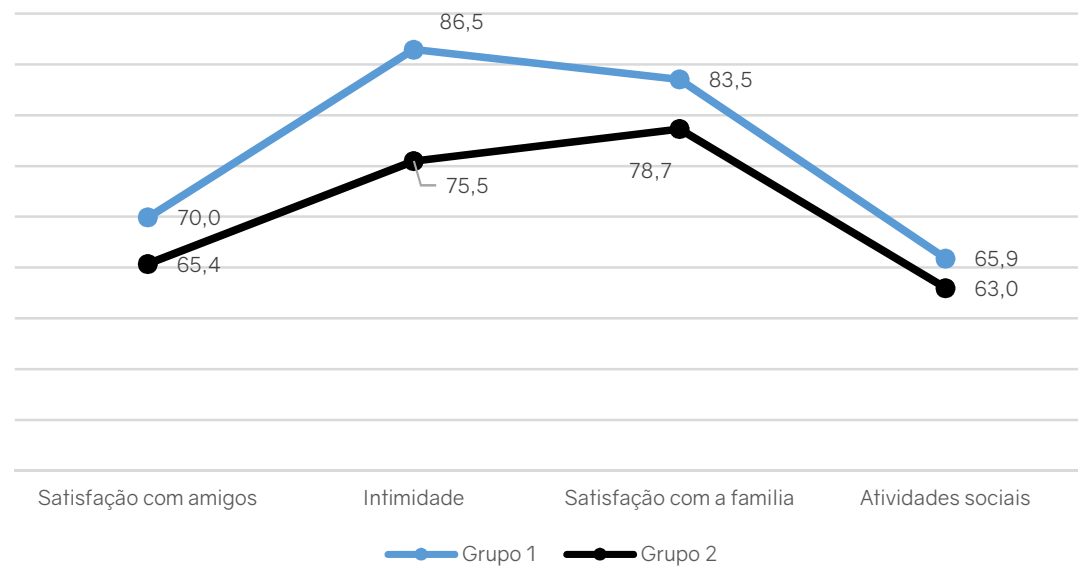

Figura 3: Diferenças Suporte social dos clusters em análise (valores normalizados1)

Tendo em conta a sua predisposição em continuar na área de enfermagem (portanto leais à opção pela profissão), o seu comportamento nas variáveis de segmentação e maior suporte social, designa-se o grupo 1 de "devotos blindados socialmente" por terem maior suporte social em todas as suas subescalas e grupo 2 de "devotos com menor suporte social" por ter menor suporte social em todas as subescalas. Na Tabela 3 é, ainda, possível observar a tipologia de estudantes "que querem mudar de curso", grupo 3, e obter informação mais pormenorizada sobre o suporte social e resiliência em todos os grupos na tipologia definida.

Antes de expor os resultados referentes ao cruzamento entre as escalas e subescalas do suporte social e da resiliência em função das tipologias obtidas refira-se que todas as dimensões apresentaram resultados aceitáveis de fiabilidade (com alphas de Cronbach acima de 0,6), com exceção na subescala "atividades sociais" (alpha de Cronbach de 0,575), sendo que, nesta subescala, os seus resultados devem ser encarados com algumas reservas. Mencione-se em primeiro lugar que o grupo dos "devotos blindados socialmente" é o grupo maioritário na amostra $(59,9 \%)$ e que o grupo "os que querem mudar" é o que tem menor representação na amostra $(11,1 \%)$. Em termos de suporte social são os que querem mudar de área que se demonstram menos revestidos de suporte social em praticamente todas as dimensões. No que toca à resiliência são os "devotos com menor suporte social" que se perfilam como os menos resilientes quer em questões de competência pessoal quer na aceitação de si próprio.

\footnotetext{
1Para fins de caracterização e comparação destes grupos, as escalas do suporte social foram submetidas a uma normalização percentual.
} 


\begin{tabular}{|c|c|c|c|c|c|c|c|}
\hline & \multicolumn{2}{|c|}{$\begin{array}{c}\text { Devotos blindados } \\
\text { socialmente } \\
(n=124 ; 59,9 \%)\end{array}$} & \multicolumn{2}{|c|}{$\begin{array}{l}\text { Devotos com menor } \\
\text { suporte social } \\
(n=60 ; 29,0 \%)\end{array}$} & \multicolumn{2}{|c|}{$\begin{array}{l}\text { Os que querem mudar } \\
\qquad(\mathrm{n}=23 ; 11,1 \%)\end{array}$} & \multirow[b]{2}{*}{$p$} \\
\hline & Média & $\begin{array}{l}\text { Desvio } \\
\text { Padrão }\end{array}$ & Média & $\begin{array}{l}\text { Desvio } \\
\text { Padrão }\end{array}$ & Média & $\begin{array}{l}\text { Desvio } \\
\text { Padrão }\end{array}$ & \\
\hline $\begin{array}{l}\text { Suporte social - } \\
\text { escala total }\end{array}$ & 60,7 & 6,8 & 56,0 & 8,2 & 52,6 & 9,5 & $<0,001$ \\
\hline $\begin{array}{l}\text { Satisfação com } \\
\text { amigos }\end{array}$ & 21,0 & 2,6 & 19,6 & 3,0 & 19,1 & 3,4 & $<0,05$ \\
\hline Intimidade & 17,3 & 2,6 & 15,1 & 3,3 & 14,1 & 3,7 & $<0,001$ \\
\hline $\begin{array}{l}\text { Satisfação com a } \\
\text { família }\end{array}$ & 12,5 & 2,2 & 11,8 & 2,2 & 10,6 & 2,9 & $<0,05$ \\
\hline Atividades sociais & 9,9 & 2,7 & 9,5 & 3,0 & 8,8 & 2,7 & 0,189 \\
\hline $\begin{array}{l}\text { Resiliência - Escala } \\
\text { total }\end{array}$ & 144,7 & 8,2 & 119,8 & 12,4 & 132,3 & 15,8 & $<0,001$ \\
\hline $\begin{array}{l}\text { Competência } \\
\text { Pessoal }\end{array}$ & 101,9 & 6,0 & 83,7 & 8,3 & 94,4 & 10,0 & $<0,001$ \\
\hline $\begin{array}{l}\text { Aceitação de si } \\
\text { próprio }\end{array}$ & 42,8 & 5,0 & 36,1 & 6,3 & 37,9 & 6,8 & $<0,001$ \\
\hline
\end{tabular}

Tabela 3 - Suporte social e Resiliência consoante tipologia de estudantes de enfermagem

Da Tabela 4 ressalta uma maior representação de estudantes do primeiro ano no grupo dos "devotos blindados socialmente" e existe uma proporção significativamente inferior de estudantes cuja opção pelo curso de enfermagem constituiu uma primeira escolha no grupo "os que querem mudar".

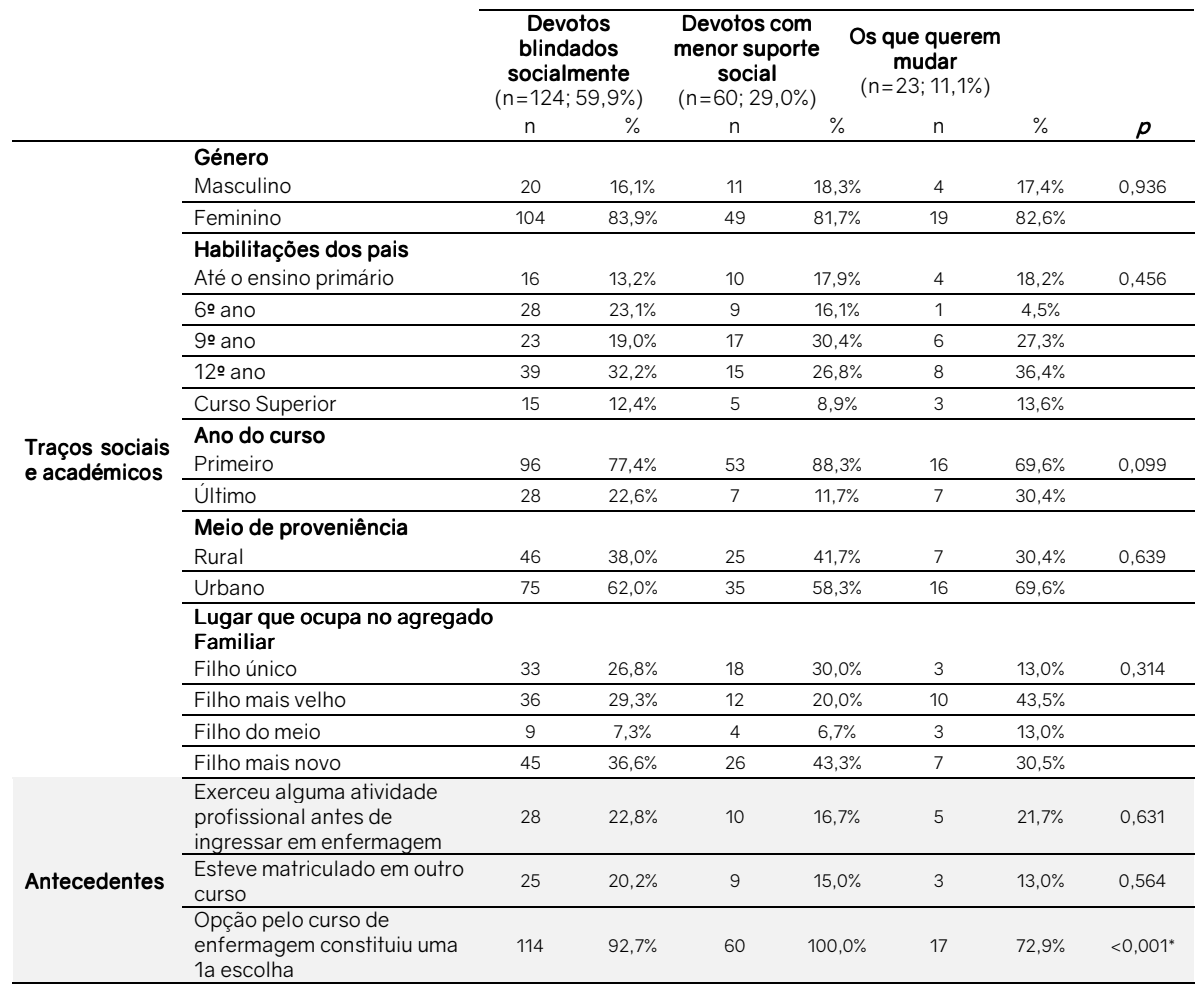

Tabela 4 - Caracterização da tipologia de estudantes de enfermagem de acordo com os traços sociais e antecedentes 


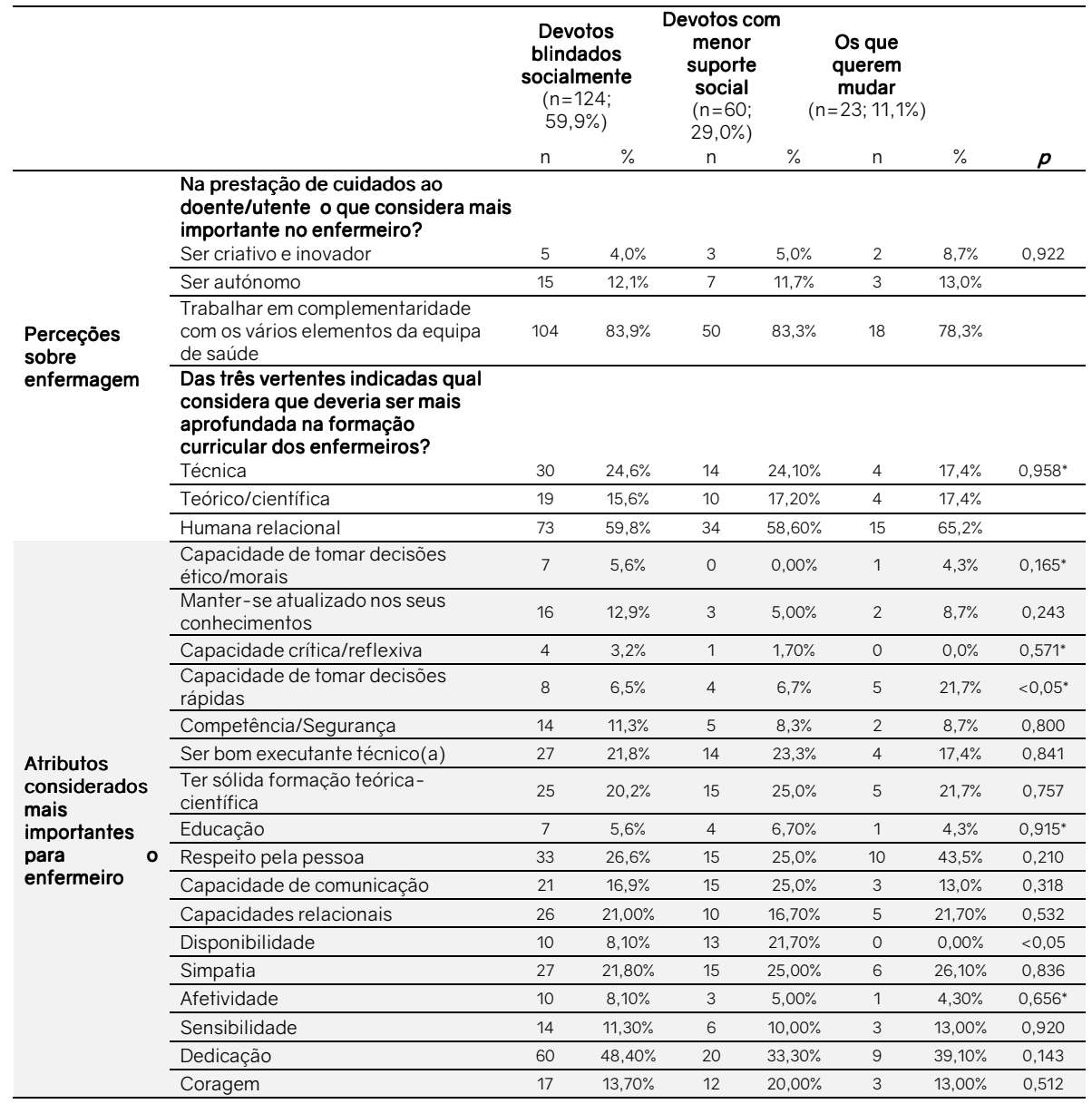

Tabela 5 - Caracterização dos grupos de acordo com as perceções e opiniões sobre enfermagem

A partir da análise da Tabela 5 constata-se que foram detetadas relações estatisticamente significativas entre a importância atribuída aos atributos: a capacidade de tomar decisões rápidas e a disponibilidade, sendo que, "os querem mudar" estão mais propensos a priorizar a capacidade de tomar decisões rápidas e "os devotos com menor suporte social" atribuem maior importância à disponibilidade.

Foram poucas as relações estatisticamente significativas detetadas entre as perceções sobre enfermagem e a tipologia de estudantes de enfermagem face ao número de cruzamentos efetuados. Apenas se verificou no grupo dos que pretendem mudar de área a atribuição de maior importância à capacidade de tomar decisões rápidas no exercício da profissão de enfermeiro. Por sua vez, os "devotos com menor suporte social" dão maior importância à disponibilidade. Muito embora não se tenha constatado relação com significância estatística é notório que o grupo dos "devotos blindados socialmente" dão maior importância à dedicação enquanto atributo, que os demais. 


\section{CONCLUSÃO}

Na profissão de enfermagem é tradicional a predominância do sexo feminino (Pimentel et al, 2011). Este facto tem sido várias vezes analisado em estudos ligados à construção identitária da profissão (Fonseca e Silva, 2012; Bevis, Watson, 2005; Tzeng, 2006; Fonseca et al, 2013; Cruz e Lopes, 2013; Brodie et al, 2004; Silva e Ferreira 2012; Sheila e Padilha, 2016; Pires, 2009; Henderson, 2004) e explicado através da evolução histórica da prática dos cuidados correntes. Durante milhares de anos, a prática dos cuidados correntes, os cuidados que suportam a vida liga-se fundamentalmente à atividade dos diversos papeis que foram sendo atribuídos à mulher ao longo do desenvolvimento das sociedades, fruto da divisão social do trabalho. Desde os tempos mais recuados da história da humanidade até ao fim da Idade Média, havia uma identificação da prática de cuidados com a mulher - papel modelado em torno da fecundidade e de todas as formas simbólicas que gera. Também o passado da prática dos cuidados de enfermagem quer cultural quer socialmente, esteve associado às mulheres cristãs - papel prescrito pelas regras conventuais. Acresce que o facto da Enfermagem se constituir maioritariamente como profissão feminina não tem comprometido o seu reconhecimento profissional interferindo no seu status social e na sua identidade profissional (Sheila e Padilha 2016; Pimentel et al, 2011).

Por sua vez, apesar de aos alunos de enfermagem ser reconhecido elevado grau de heterogeneidade e as prioridades com que concorrem ao curso, à semelhança do que acontece com outros cursos do Ensino Superior, estarem mais relacionadas com as leis do mercado do que com a apetência por determinada profissão é possível constatar que é elevado o valor percentual dos alunos que fizeram do curso de enfermagem a sua primeira escolha, assumindo esse valor maior expressividade no grupo do 10 ano. Conhecidas as múltiplas circunstâncias associadas no acesso ao Ensino Superior e não obstante a indefinição que muitas vezes acompanha a escolha de determinada profissão, poderá admitir-se que o elevado interesse em primeiro lugar pelo curso de enfermagem, apenas 7,6\% declararam não ter sido o curso de enfermagem a sua primeira escolha, evidencia uma possibilidade maior do gosto pela profissão.

A construção de uma tipologia de estudantes de enfermagem através de uma análise de clusters, identificando classes, subconjuntos de registos que representam valores mais próximos em certos atributos chegámos a três grupos.

A partir dos estudantes que não têm intenção de mudar de área profissional e da subamostra dos estudantes que têm a intenção de mudar procedeu-se a uma tipologia de estudantes de enfermagem, tendo como variáveis de segmentação as subescalas de satisfação com o suporte social. Designámos o grupo 1 de "devotos blindados socialmente" por terem maior suporte social em todas as suas subescalas e o grupo 2 de "devotos com menor suporte social" por ter menor suporte social em todas as subescalas. Acresce a tipologia de estudantes "que querem mudar de curso", grupo 3.

O grupo dos "devotos blindados socialmente" é maioritário $(59,9 \%)$ ao contrário do grupo "os que querem mudar" com menor representação na amostra (11,1\%). Em termos de suporte social são os que querem mudar de área que se demonstram menos revestidos de suporte social em praticamente todas as dimensões. No que toca à resiliência são os "devotos com menor suporte social" que se perfilam como os menos resilientes quer em questões de competência pessoal quer na aceitação de si próprio.

Releva, ainda, uma maior representação de estudantes do primeiro ano no grupo dos "devotos blindados socialmente" e existe uma proporção significativamente inferior de estudantes cuja 
opção pelo curso de enfermagem constituiu uma primeira escolha no grupo "os que querem mudar".

Foram poucas as relações estatisticamente significativas detetadas entre as perceções sobre enfermagem e a tipologia de estudantes definida. Apenas se verificou no grupo dos que pretendem mudar de área a atribuição de maior importância à capacidade de tomar decisões rápidas no exercício da profissão de enfermeiro. Por sua vez, os "devotos com menor suporte social" dão maior importância à disponibilidade. Muito embora não se tenha constatado relação com significância estatística é notório que o grupo dos "devotos blindados socialmente" dão maior importância à dedicação enquanto atributo percecionado de ligação à profissão, que os demais.

A identidade de uma profissão é produzida pela articulação entre as trajetórias individuais e sociais, onde a história e o poder se interpenetram. Assumindo que a as instituições de ensino superior representam uma etapa desafiante à capacidade de adaptação de qualquer jovem é da responsabilidade dessas instituições a promoção do bem-estar, da identidade social e profissional da profissão que escolheram, bem como a aquisição de competências (BolsoniSilva e Loureiro, 2016) que contribuam para o desenvolvimento global e estabilidade emocional dos estudantes (CASEL, 2015).

A preocupação com o desenvolvimento de competências transversais e específicas ao longo do percurso académico é uma realidade em crescendo, quer nacional quer internacionalmente (Savoji e Ganji, 2013; Selemat, Ismail, Ahmad, Hussin, Seliman, 2013; Shek, 2013). Estes autores têm realçado a importância dos currículos dos cursos superiores integrarem o desenvolvimento de competências pessoais e interpessoais que, tornando-se ferramentas úteis para os estudantes, aumentem o sucesso académico e profissional, prevenindo por consequência o desajustamento psicoemocional. Tendo em conta os resultados do nosso estudo, maior satisfação com o suporte social e níveis mais elevados de resiliência parecem capacitar os jovens estudantes que optam pela área profissional de enfermagem.

Uma maior representação de estudantes do primeiro ano no grupo dos "devotos blindados socialmente" indicia que a formação adquirida ao longo do curso não terá sido decisiva na afirmação da identidade profissional. De igual forma, a proporção significativamente inferior de estudantes cuja opção pelo curso de enfermagem constituiu uma primeira escolha no grupo "os que querem mudar" remete para a valorização profissional dos que fizeram da enfermagem a sua primeira escolha, anterior à entrada no curso.

\section{BIBLIOGRAFIA}

Bacchi, S., Licinio, J. (2016). Resilience and psychological distress in psychology and medical students. Academic Psychiatry, 5 (3), 1-4.

Bevis, O. \& Watson, J. (2005). Rumo a um Curriculum de Cuidar: Uma Nova Pedagogia para a Enfermagem. Lisboa: Lusociência.

Silva, B., Turini A. \& Loureiro, R. (2016). Validação do Questionário de Avaliação de Habilidades Sociais, Comportamentos, Contextos para Universitários. Psicologia: Teoria e Pesquisa, 32 (2), 1-10

Brodie, D. A., Andrews, G.J., Andrews, J.P., Thomas, G.B., Wong, J. \& Rixon, L. (2004), Perceptions of nursing confirmation, change and the student experience., International Journal of Nursing Studies., 41(7), 721-33.

Carvalho, A., Almeida C., Amann, G., Leal, P., Marta, F., Pereira, F., Ladeiras, L., Lima, R \& Lopes, I. (2016). Saúde Mental em Saúde Escolar. Manual para a Promoção de Competências Socioemocionais em meio escolar. Lisboa: Ministério da Saúde. - Direção-Geral da Saúde. 
CASEL (2015). Effective social and emotional learning programs. Middle and high school edition. New York: Casel.

Collière, M. F. (2000). Promover a vida. Lisboa: Lidel.

Decreto-Lei n.o no 247, de 22 de setembro de 2009. Diário da República no 184 - I Série A. Lisboa: Ministério da saúde

Decreto-Lei n.o 161/96, de 4 de setembro. Diário da República oo 205 - Série A. Regulamento do Exercício Profissional do Enfermeiro (REPE). Lisboa: Ministério da saúde

Dubar, C. (2009). A crise das identidades: a interpretação de uma mutação. São Paulo: Universidade de São Paulo.

Erikson, E. (1976). Identidade, juventude e crise, 2a ed. Rio de Janeiro: Zahar Editores.

Ferreira de Carvalho, C. A. \& Leal, I. P. (2012). Adaptação da The Resilience Scale para a população adulta portuguesa. Psicologia USP, 23 (2), 417-433.

Fonseca, A., Lopes, M. J.; Sebastião, L. \& Magalhães, D. (2013). Conhecimento em Enfermagem: representações sociais construídas por estudantes de formação inicial. in F. Mendes, L. Gemito, D. Cruz \& M. Lopes (org). Enfermagem Contemporânea, (pp-30-43). Évora: Universidade de Évora.

Fonseca, L., Silva, F. \& Paes, M. J. (2012). Desafiando a imagem milenar da Enfermagem perante adolescentes pela internet: impacto sobre suas representações sociais. Ciencia Cuidado e Saúde; 11 (suplem.), 54-62.

Ha Do, T. \& Khanitta, N. (2016), Perceptions of How Negative Nursing Image Impacts on Nursing Care and Nursing Competency Development. 4th Asian Academic Society International Conference (AASIC), 254-262.

Hair Jr., J. F., Black, W. C., Babin, B. J., Anderson, R. E. \& Tatham, R. L. (2009), Análise multivariada de dados, 5a ed. Porto Alegre: Bookman.

Henderson, V. (2004). ICN's Basic Principles of Nursing Care. Geneva: ICN.

Kovás, M, J. (2002). Morte e desenvolvimento humano. São Paulo: Casa do Psicólogo.

Marôco, J. (2014), Análise Estatística com utilização do SPSS, 6ạ ed. Lisboa: Edições Sílabo.

Pais Ribeiro, J. L. (1999), Escala de Satisfação com o Suporte Social (ESSS). Análise Psicológica, 17 (3), 547-558.

Pais Ribeiro, J. L. (2011). Satisfação com o Suporte Social. Lisboa: Placebo Editora.

Pimentel, M. H., Mata, M. A. P. \& Pereira, F. A. (2011). The Construction of Social and Professional Identity of a Feminine Profession: Nursing. Prismasocial (7), 1-23.

Pinto, J. M. (1991). Considerações sobre a produção social de identidade. Revista Crítica de Ciências Sociais (32), 217-231.

Pires, D. (2009). Enfermagem enquanto disciplina, profissão e trabalho. Revista Brasileira de Enfermagem. 62 (5), 739-44.

Savoji, A. P. \& Ganji, K. (2013). Increasing mental health of university students through life skills training (LST). Procedia - Social and Behavioral Sciences, 84, 1255-1259.

Selamat, J,, Khaidzir, I., Hj; Ahmad A. \& Hussin, M. H., (2013). Framework of soft skills infusion based on learning contract concept in Malasyia higher education. Asian Social Science, 9 (7).

Sharma, G. \& Sharma, P. (2010). Importance of soft skills development in 21st century curriculum. International Journal of Education and Allied Sciences, 2 (2), 39-44.

Teodosio, S. S. C. \& Padilha, M. I. (2016). Ser enfermeiro: escolha profissional e a construção dos processos identitários (anos 1970), Revista Brasileira de enfermagem, 69 (3), 428-34.

Shek, D. T. L. (2013). Promotion of holistic development in university students: A credit-Bearing course on leadership and intrapersonal development. Best Practices in Mental Health, 9 (1), 47-61. 
Silva, R. C., \& Ferreira, M. A. (2012). Construindo o roteiro de Entrevista na pesquisa em Representações Sociais: Como, por que, para quê?. Escola Anna Nery, 16 (3), 607-611.

Silva, G. S. N. (2012). A racionalidade médica ocidental e a negação da morte, do riso, do demasiadamente humano, in V. A. Angerami (Org.), Psicossomática e suas Interfaces: O processo silencioso do adoecimento (pp-83-117). São Paulo: Cengage: Learning.

Siqueira, M. M. M. (2008). Construção e validação da Escala de Percepção de Suporte Social. Psicologia em Estudo, 13 (2), 381-388.

Soares A. M., Pereira M. \& Canavarro, J.P. (2014). Saúde e Qualidade de Vida na Transic , ão para o Ensino Superior. Psicologia, Saúde e Doenc, as, 15(2), 356-379.

Tzeng, H. M. (2006), Testing a conceptual model of the image of nursing in Taiwan. International Journal of Nursing Studies, 43 (6) 755-65.

Wagnild, G. M.; Collins, J. A. (2009), Assessing resilience. Journal of Psychosocial Nursing, 47(12), 28-33. 